\title{
Curriculum System Research on Talent Training Mode of "School-enterprise integration" in Hotel Management Major
}

\author{
Quan-Jun Zheng, You-Rong Xiao, Xiu-Juan Jiang \\ Hainan College of Software Technology, QiongHai, Hainan 571400, China \\ Zhengqj67@126.com Xiaoyor69@126.com 01051726@sina.com
}

\begin{abstract}
The curriculum system on talent training mode of school-enterprise integration in higher vocational college must based on the working process systematic curriculum system, the development of which follow the process of "Post (group) investigation analysis and research(including processional growth phase nanlysis) $\rightarrow$ work task decomposition $\rightarrow$ action in induction $\rightarrow$ learning areas conversion $\rightarrow 1$ earning situation design". This thesis sets example of curriculum system development of hotel management major to research the construction of curriculum system on talent training mode of school-enterprise integration in higher vocational college.

Index Terms - Hotel management major, Systematic working process, Curriculum system
\end{abstract}

\section{Introduction}

The curriculum system is a knowledge combination system having specific function and special structure. The system struction not only should make the major's basic skills course, professional post course, career building skills course into a unity, but also should reflect accurately the foster professional goals and professional specifications to adapt to the needs of social economic development ${ }^{[1]}$. The troditional curriculum system-from base to major, from theoretical knowledge to application skills-has not made the needs of the talent training mode of "school-enterprise intrgration" which must be the curriculum system based on systematic working process.

\section{The Development Process Based on the Curriculum System of Systematic Working Process}

The development process based on the curriculum system of systematic working process firstly investigates professional post to find working task of every job; then deducees typical task from society and enterprise's key task; thirdly constructs learning area based on typical working task, every typical working task constitudes a learning area; at last design teaching project for every learning area to cinstruct learning environment ${ }^{[2]}$. The step is briefly elaborated as "Post (group) analysis and research (including processional growth phase nanlysis) $\rightarrow$ work task decomposition $\rightarrow$ action in induction $\rightarrow$ learning areas conversion $\rightarrow$ learning situation design", the specific process is like the figure $1^{[3]}$.

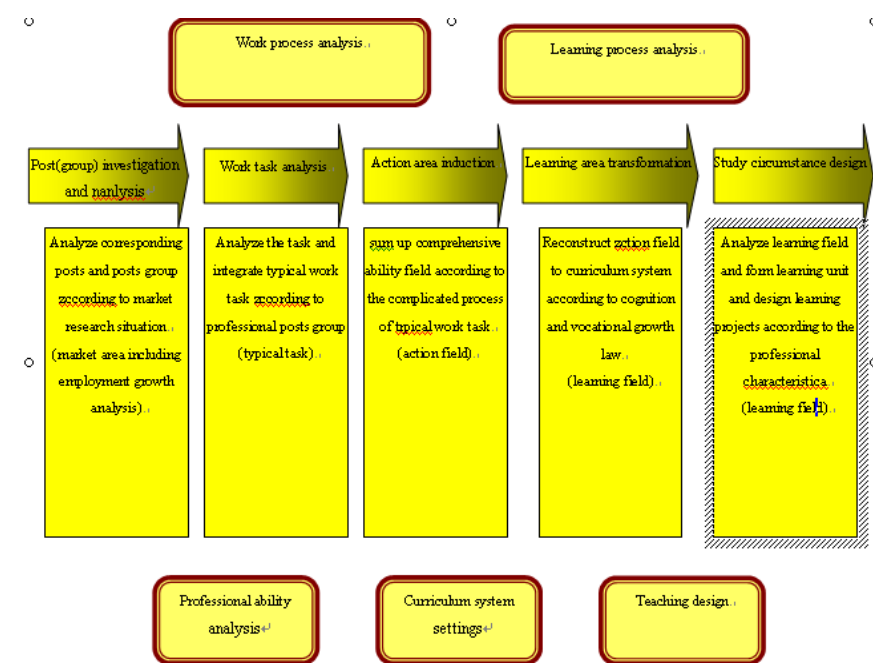

Figure 1: The curriculum system development flowchart based on systematic work process

Post (group) analysis is to investigate and analyze comprehensively and systematicly a student trained by a major may do a work's task, property, duty and the worker 's basic knowledge, basic skill and comprehensive quality, to objectively describe and take regular record, and to study, analyze and refine the jobs students may engage in the future, the jobs include both the posts graduates employed directly and the posts (expand post) after a long time (5 to 10 years) hard work students qualified. After in-depth analysis of post group, the law of growth is proposed.

Work task decomposition is to decompose and analyze the knowledge, skill, ability the post needs and other comprehensive skills through work proecss analysis, and then to decide work task, to analyze integratedly the job according to the logic of professional development, to extract the general tasks and to integrate typical work tasks to sum up action areas.

Action field induction is that induce and integrate every work task in the working process of typical work task to form all skills, knowledge and ability needed by post group work task. That is to say that it is not settinf up a course to every typical work task, but to further analyze the typical task and extract action field so as to bring it to learning field.

Learning field transformation bases on a professional typical task, analyzes action field and then transform it into learning according to the requirements of the working process 
of post ability. The learning field is found from professional activity by scientific methods through congnitive learning law and vocational growth law but not constructed by subjuctive fictition. "That is teaching process should take the working process of typical professional activity corresponded by a major as orirent[4]."

Learning circonstance design is to make learning field curriculum standards. It is impotant and difficult point to the development curriculum based on systematic working process. Its contents include curriculum description, introduction of curriculum taget, curriculum design, curriculum implementation, teaching assessment, curriculum resources.

\section{The Cueeiculum System Development Based On Systematic Working Process In Hotel Management Major}

\subsection{Post(group) investigation analysis}

The implementers of post (group) investigation analysis are all members of curriculum development project group, the technical route used is to survey various types of hotel, the final result is to form the need of professional post group and the orientation of training objectives. It is understood through various means that the employment areas of hotel management major graduates include all star hotel, restaurants, cafes, bars, western reataurants, entertainment field etc, and the post group of hotel management major are hotel service post, management skill post and bar management post. And the management skill post is departed to front office management post, food and bevetage management post and guest room management post etc. The developed expanding posts are dieticians, bartenders, convention and exhibitionservices and other related jobs. The training target of hotel management specialty is to cultivate high-quality and high skill applied management expertise who owns good moral, proper etiquette and can fully master basic theory of modern hotel management and be faniliar with basic skill of hotel service and hotel management. The careed growth rules of hotel management major should be a gradually advanding process of work ability $\rightarrow$ job-hunting ability $\rightarrow$ creative ability, like figure2:

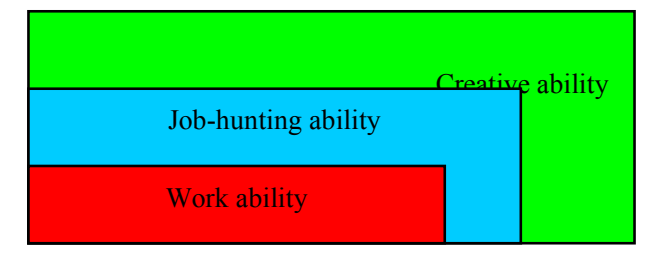

Figure2: The professional development ladder figure of hotel management professional talents

\subsection{Work task decomposition}

The implementers of work task decomposition are practice experts of curriculum development project group, the technical route used is holding the interview of practice experts to analyze work task, the final result is to extract typical work task, then get the typical work task corresponded by hotel management major post group. The typical work tasks corresponded by hotel service post are service work of all post in hotel sectors. The typical work tasks corresponded by front office management post are front office management and day-to-day management work. The typical work tasks corresponded by food and beverage management post are food and beverage management and day-to-day management work of the hotel. The typical work tasks corresponded by guest room management post are housekeeping management and day-to-day management work. The typical work tasks corresponded by bar management posts are the bar operation and management.

\subsection{Action in induction(including ability analysis)}

The implementers of action in induction are practice experts of curriculum development project group, the technical route used is inducing professional action field through analyze, the final result is to induce the action field corresponded by typical work task in hotel management major. The action fields correponded by service work in hotel service post are front office service, housekeeping service, catering service, conference service, recreation and sports service, bar service and beverage deployment etc. The action fields correponded by front office management and day-to-day management work are guest room price management, quality control, sales management, front office information management and personnel management etc. The action fields correponded by food and beverage management and day-today management work in hotel are raw materials management, production management, service management, sales management, financial management, catering information management and personnel management etc. The action fields correponded by housekeeping management and day-to-day management work are guest room design and environmental management, quality control of guest rooms, rooms supplies management, room equipment management, rooms safety management, room budget management, rooms business planning and reconstruction, room information management and personnel management etc. The action fields correponded by bar operation and management are management before buisiness, business management and management after business.

\subsection{Learning areas conversion}

The implementers of learning areas conversion are major leaders and backbone teachers of curriculum development project group, the technical route used is to order knowledge structure through action field analysis and professional ability analysis, the final result is cinverse into learning field to make the curriculum field structure figure. The learning field system of hotel management major is like figure 3 through the analusis to hotel management major aceion field:

\subsection{Learning circumstance design}

The implementers of learning areas conversion are major leader and backbone teachers of curriculum development 
project group, the technical route used is to extract teaching centent and design teaching method through analyzing the curriculum's position in major learning area. The final result is designing learning circumstance. Here setting the course-
FoodService and Management as example to simply prove the learning ciecumstance design based on systematic work process, like chart 1:

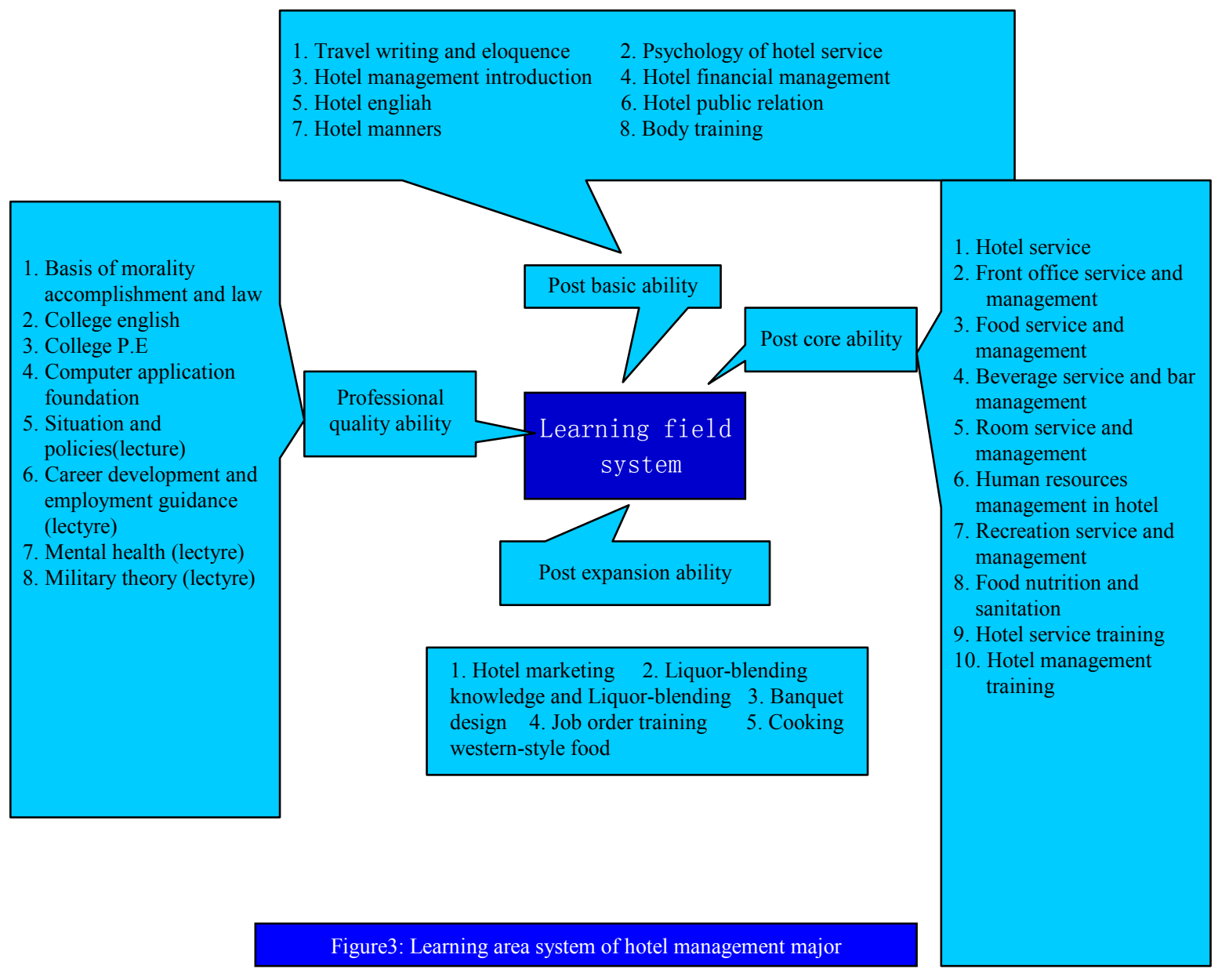

Chart1: Learning circumstance design chart of FoodService and Management course

\begin{tabular}{|c|c|c|c|c|c|}
\hline Nature of Course: Core Course & Total periods : 120 hours & \multicolumn{2}{|c|}{ Term for the Course: the Forth Term } & \multicolumn{2}{|c|}{ Form: Theory + Practice } \\
\hline \multicolumn{6}{|c|}{$\begin{array}{l}\text { Training Target : } \\
\text { The course is to train the grass-roots attendants, captains, supervisors, and managers for hotels and catering industry with necessary } \\
\text { theory and skills. The detailed description is as follows: } \\
\text { 1. Through service skills training and service process learning, students will be able to conduct Chinese food service, western food } \\
\text { service and other organization and reception work. } \\
\text { 2. Through the study of material management, production management and service management, students will be able to manage the } \\
\text { raw materials and production in the food \& beverage department, design menu and monitor service quality. }\end{array}$} \\
\hline \multicolumn{6}{|l|}{ Teaching Contents : } \\
\hline Learning Circumstances & 1 & 2 & 3 & & 4 \\
\hline Chinese Food Services & Breakfast Services & Dinner Services & Buffet Serv & & Banquet Services \\
\hline Western Food Services & Dinner Services & Banquet Services & Reception Se & & \\
\hline Service Management & $\begin{array}{c}\text { Catering Materials } \\
\text { Management }\end{array}$ & $\begin{array}{c}\text { Catering Production } \\
\text { Management }\end{array}$ & $\begin{array}{r}\text { Menu Desigr } \\
\text { Making }\end{array}$ & & $\begin{array}{l}\text { Service Quality } \\
\text { Monitoring }\end{array}$ \\
\hline \multicolumn{6}{|c|}{ Teaching Place : classroom + hotel $($ simulated hotel $)$} \\
\hline \multicolumn{6}{|c|}{$\begin{array}{l}\text { Teaching Methods : combining teaching, learning and doing together, the teaching methods include lecturing, case discussion, situational } \\
\text { method, etc. }\end{array}$} \\
\hline
\end{tabular}




\section{Acknowledgment}

This thesis has received the support from the project of 2013 Hainan Psychology and Sociology Planning (HNSK (GJ) 13-122) and 2013 Teaching Reform for Hainan Vocational Education (Hngjy13-029) and 2013 scientific research items of Hainan College of Software Technology (Hr201311).Thanks a lot!

\section{References}

[1] Yue Luo; Chong-Gang Chen, Higher Vocational Movie Animation professional Curriculum System Construction. Beauty And The Times. 2010(04):67.

[2] Ke-An Zhang, Construction and implementation on Talent Training Mode of "School-enterprise integration" in Higher Vocational colleges, Research on Higher Vocational Education,. 2009(06):115.

[3] Zhan-Ming Liu, Curriculum system innovation research Based on work process - oriented Higher Vocational College Tourism specialty, Hebei Normal University, 2010(02):28.

[4] Da-Yuan Jiang Study on main teaching thought in Contemporary German vocational education, Tsinghua University Press 2007:112. 